\title{
Anti-diarrhoeal activity of aqueous extract of Cochlospermum planchonii (Hook Fx. Planch) leaves in female Wistar rats
}

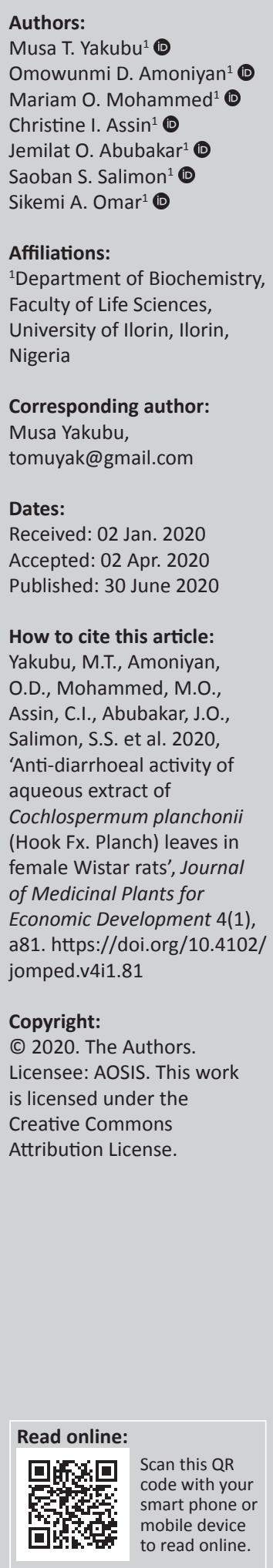

Background: The folkloric use of Cochlospermum planchonii is yet to be substantiated with scientific evidence.

Aim: The aqueous extract of C. planchonii leaves was evaluated for anti-diarrhoeal activity at 125,250 and $500 \mathrm{mg} / \mathrm{kg}$ body weight in female Wistar rats.

Setting: This research is a phytopharmacological investigation.

Methods: Animal were monitored for indicators of diarrhoea in the 3 models after treatments.

Results: An aqueous extract of $C$. planchonii leaves contained 10 secondary metabolites, with alkaloids $(16.05 \mathrm{mg} / \mathrm{L})$ occurring the most, whilst quinones $(0.7 \mathrm{mg} / \mathrm{L})$ were the least. The extract significantly $(p<0.05)$ prolonged the onset time of diarrhoea, decreased water content, fresh weight and total number of wet faeces in a dose-dependent manner, and increased the percentage inhibition of defecation. The extract produced dose-specific changes on intestinal superoxide dismutase, glucose and reduced glutathione whereas the levels of intestinal $\mathrm{Na}^{+} / \mathrm{K}^{+}$-ATPase, alkaline phosphatase, catalase, nitric oxide were significantly $(p<0.05)$ increased in the castor oil-induced diarrhoeal model. The masses and volumes of intestinal fluid decreased significantly $(p<0.05)$ whereas the inhibition of intestinal fluid content increased like those of atropine-treated diarrhoeal rats in the enteropooling model. The extract dose-dependently decreased the distance travelled by the charcoal meal and increased the intestinal nitric oxide and acetylcholinesterase in the charcoal meal transit model.

Conclusion: The aqueous extract of C. planchonii leaves exhibited anti-diarrhoeal activity via anti-motility and anti-secretory means. The flavonoids, alkaloids, tannins, phenolics and saponins might have acted to enhance the activities of $\mathrm{Na}^{+} / \mathrm{K}^{+}$-ATPase, antioxidant enzymes, intestinal glucose levels and the neurotransmitters.

Keywords: anti-diarrhoea; castor oil; Cochlospermum planchonii; Cochlospermacea; acetylcholine esterase.

\section{Introduction}

Diarrhoea is a gastrointestinal condition caused by bacteria, virus and parasitic organisms (Peter \& Umar 2018). It is characterised by increased intestinal motility, secretion and/or a decrease in the reabsorption of fluid and electrolytes (Ezeja et al. 2012). More than half of diarrhoeal cases are reported in Africa and South Asia with a resultant mortality (Peter \& Umar 2018). The incidence of diarrhoeal diseases varies greatly by seasons and age with children within the first 18 months of life being the most vulnerable (Peter \& Umar 2018). Diarrhoea is usually transmitted via the consumption of contaminated food and water or exposure to unhygienic practices in food preparation and waste disposal (Peter \& Umar 2018). Several orthodox medicines which have been developed for the treatment of diarrhoea are associated with some complications such as constipation, nausea, emesis and fatigue. Hence, there is the need to explore medicinal plants that pose little or no side effects.

Cochlospermum planchonii (family: Cochlospermacea) is a shrub that grows to about $2 \mathrm{~m}-2.5 \mathrm{~m}$ tall. It is widespread in the tropical regions from Senegal to Cameroun. It also grows in the Northern part of Nigeria, especially the Chambas of the Vogel peak area (Benue River Valley, Taraba State). Cochlospermum planchonii is commonly known as Gbehutu or Feru amongst the Yoruba tribe - in Western Nigeria (Ior et al. 2011). The plant was reportedly used in ethnomedicine for the treatments of schistosomiasis, jaundice, fever, back pain, intestinal worms, bilharziasis, hepatitis, diabetes, infertility and diarrhoea (Burkill 1985). The fresh root of the plant was also 
used as a concoction together with fresh stem bark of Erythrina senegalensis for the treatment of stomach disorder, typhoid and urinary tract infection (Togotla et al. 2008). The root decoction is used for the treatment of uncomplicated malaria caused by Plasmodium falciparum without any major side effects (Adjanahoun et al. 1991).

Nafiu, Akanji and Yakubu (2011) reported the presence of saponins $(7.5 \%)$, phenolics $(3.16 \%)$, alkaloids $(2.92 \%)$, steroids $(0.89 \%)$, tannins $(0.15 \%)$, flavonoids $(0.07 \%)$, triterpenes $(0.09 \%)$ and anthraquinones $(0.19 \%)$ in the aqueous extract of C. planchonii roots. Anti-malarial (Beniot-Vical et al. 2003), anti-bacterial (Ouattara et al. 2007), analgesic and anti-inflammatory (Ior et al. 2011), anti-diabetic and antidyslipidemic activities (Bamisaye et al. 2017) of the plant extract have been reported. Studies have also been documented on the plant with respect to the fertility enhancing activities of bioactive components of the C. planchonii rhizome on cisplastin-induced reproductive dysfunction in Sprague Dawley rats (Adelakun, Agboola \& Akingbade 2018); increased spermatogenesis in male rats by aqueous ethanolic extract (Abu, Ochalefu \& Ibrahim 2012) and toxicity of aqueous root extract of $C$. planchonii in selected tissues of mice (Nafiu, Akanji \& Yakubu 2013). Furthermore, the anti-diabetic activity of the aqueous extract of the $C$. planchonii root in alloxan-induced diabetic rats (Yakubu, Akanji \& Nafiu 2010), and the anti-diabetic activity and free radical modulatory potentials of the saponin-rich extract of the C. planchonii root in vitro (Ashafa \& Nafiu 2018) have been established. Despite the myriads of published studies on the pharmacology and toxicity of C. planchonii, none, to the best of our ability, has reported the anti-diarrhoeal activity of the plant. The present study was, therefore, aimed at investigating the anti-diarrhoeal activity of the aqueous extract of $C$. planchonii leaves in female Wistar rats using the standard diarrhoeal models.

\section{Materials and methods Plant collection and identification}

Fresh leaves of $C$. planchonii obtained from a farmland at Oke Odo, Tanke, Ilorin, Kwara State, Nigeria, were authenticated at the Herbarium Unit of the Department of Plant Biology, University of Ilorin, Ilorin, where a voucher specimen (UILH/001/922) was deposited.

\section{Preparation of plant extract}

Cochlospermum planchonii leaves were washed under running tap water and oven-dried (Uniscope Laboratory Oven, SM9053, Surgifield Medicals, England) at $40{ }^{\circ} \mathrm{C}$ for $24 \mathrm{~h}$. Afterwards, the dried leaves were pulverised using an electric blender (FINLAB Nigeria Limited, Ilupeju Industrial Scheme, Lagos, Nigeria) and kept in an air-tight container prior to extraction. A known amount $(80 \mathrm{~g})$ of the powdered sample was extracted in $800 \mathrm{~mL}$ of distilled water for $24 \mathrm{~h}$ and filtered using Whatman No.1 filter paper. The resulting filtrate was lyophilised with a Zirbus Lyophiliser, (Model VaCo 5-11, Zirbus Technology, Stephensonstraat, Germany) to yield $7.76 \mathrm{~g}$, corresponding to a percentage yield of $9.7 \%$. This was reconstituted in distilled water to obtain the required doses of 125, 250 and $500 \mathrm{mg} / \mathrm{kg}$ body weight (calculated based on information from ethnobotanical survey) used in this study.

\section{Experimental animals}

Healthy, female Wistar rats (Rattus norvegicus) weighing $142.01 \pm 7.33 \mathrm{~g}$ were obtained from Markeen Nigeria Global Ventures, Ilorin, Kwara State, Nigeria. The animals were housed in clean wooden cages placed in well-ventilated housing conditions (temp: $25^{\circ} \mathrm{C}-27^{\circ} \mathrm{C}$; photoperiod: about a $12 \mathrm{~h}$ light and dark cycle; relative humidity: $45 \%-50 \%$ ). The animals were allowed unrestricted access to clean rat pellets (Top Feeds Nigeria Limited, Ibadan, Nigeria) and tap water. The cages were cleaned on a daily basis.

\section{Drugs and chemicals}

Loperamide hydrochloride, castor oil and atropine sulphate were products of Euro Life Health-care Pvt. Ltd, Uttarakhand, India; Yafah N-10 Limited, Egbejila, Ilorin, Kwara State, Nigeria, and Laborate Pharmaceuticals, Ind. Area, Panipat, India respectively. Nutrient Agar was obtained from Lab M Limited, Heywood, Lancashire, United Kindom. All other reagents used in this study were of analytical grade and prepared according to specifications using standard volumetric flasks and distilled water.

\section{Experimental design}

For each diarrhoeal model, 42 female Wistar rats were randomised into six groups (I, II, III, IV, V and VI) of 7 animals each and treated as described:

- Group I - Distilled water only

- Group II - Castor oil + Distilled water

- Group III - Castor oil + Reference drug (as applicable to each model)

- Group IV - Castor oil + $125 \mathrm{mg} / \mathrm{kg}$ body weight of aqueous extract of $C$. planchonii leaves

- Group V - Castor oil + $250 \mathrm{mg} / \mathrm{kg}$ body weight of aqueous extract of $C$. planchonii leaves

- Group VI - Castor oil + $500 \mathrm{mg} / \mathrm{kg}$ body weight of aqueous extract of $C$. planchonii leaves

The experimental procedure was conducted in line with the Guidelines for the Care and Use of Laboratory Animals of the National Research Council (NRC 2011) and those of the Department of Biochemistry, University of Ilorin, Ilorin, Nigeria (BCH/UIL/15/2018).

\section{Secondary metabolite screening}

The aqueous extract of $C$. planchonii leaves were screened for the presence of phenolics, quinones, coumarins, steroids, cardiac glycosides, flavonoids, alkaloids, saponins, tannins, and terpenoids using standard procedures described by Harborne (1973) and Odebiyi and Sofowora (1978). The 
quantification of the detected secondary metabolites was conducted as described for phenolics (Ragazzi \& Veronese 1973), saponins (Hudson \& El-Difrawi 1979), tannins (Swain 1979), alkaloids (Harborne 1973), flavonoids (Lamaison \& Carnet 1990), cardiac glycosides (Solich, Sedliakova \& Karlicek 1992), quinones, terpenoids and coumarins (El-Olemy, Al-Muhtadi \& Afifi 1994).

\section{Castor oil-induced diarrhoea}

The method described by Sunil et al. (2001) was adopted with slight modification. The rats were fasted for $8 \mathrm{~h}$ prior to the experiment without food but water. Each animal was placed in a cage that has its floor lined with pre-weighed blotting paper. Animals in groups I and II received $1 \mathrm{~mL}$ of distilled water each whilst the rats in groups III, IV, V and VI were administered $2.50 \mathrm{mg} / \mathrm{kg}$ body weight of loperamide hydrochloride, 125, 250 and $500 \mathrm{mg} / \mathrm{kg}$ body weight of the extract, respectively. Half an hour later, all of the animals were treated with $1 \mathrm{~mL}$ of castor oil, except for the animals in group I that were again treated with $1 \mathrm{~mL}$ of distilled water. The time between the administration of castor oil and the appearance of the first diarrhoeal faeces was recorded whilst the severity of diarrhoea was noted at an interval of $1 \mathrm{~h}$ for a total period of $6 \mathrm{~h}$. This was achieved by monitoring the diarrhoeal drops on the blotting paper placed under the rat cages. Afterwards, the faecal parameters (total number of faeces, diarrhoeal faeces, fresh weight and water content of faeces) were determined whilst the percentage inhibition of defecation was computed. At the end of the observation period, the animals were sacrificed as described by Akanji and Yakubu (2000). The small intestine supernatants were prepared and assayed for the activities of $\mathrm{Na}^{+} / \mathrm{K}^{+}$-ATPase, catalase, superoxide dismutase (SOD), alkaline phosphatase and concentrations of intestinal glucose and reduced glutathione.

\section{Castor oil-induced enteropooling}

This was determined by adopting the procedure described by Havagiray, Ramesh and Sadhna (2004) with slight modifications. The animals were briefly fasted as described earlier. Animals in groups I and II received, orally, $1 \mathrm{~mL}$ of distilled water each. The animals in groups III were intramuscularly administered $1 \mathrm{~mL}$ of atropine sulphate corresponding to $1 \mathrm{mg} / \mathrm{mL}$, whilst those in groups $\mathrm{IV}, \mathrm{V}$, and VI were orally administered $1 \mathrm{~mL}$ corresponding to 125, 250 and $500 \mathrm{mg} / \mathrm{kg}$ body weight of the extract, respectively. Immediately after the administration, all the animals were administered $1 \mathrm{~mL}$ of castor oil, except for the animals in group I that received $1 \mathrm{~mL}$ of distilled water. The rats were sacrificed $30 \mathrm{~min}$ post-administration of castor oil as described by Akanji and Yakubu (2000). The small intestine was excised and the intestinal content was squeezed into a measuring cylinder. The masses and volumes of the intestinal content were obtained whilst the percentage inhibition of intestinal fluid content was also computed using the following expression:
Inhibition of intestinal content $(\%)=$ Mass of intestinal

fluid $(\mathrm{g})\left(\frac{\text { Control }- \text { Treated }}{\text { Control }}\right) \times 100$

[Eqn 1]

\section{Gastrointestinal motility}

The method described by Gerald et al. (2007) was adopted for this model. The animals were fasted as described earlier. Animals in groups I and II received orally, $1 \mathrm{~mL}$ of distilled water each. Animals in groups III were intramuscularly administered $1 \mathrm{~mL}$ corresponding to $1 \mathrm{mg} / \mathrm{mL}$ of atropine sulphate, whilst those in groups IV, V and VI received orally, $1 \mathrm{~mL}$ corresponding to, 125, 250 and $500 \mathrm{mg} / \mathrm{kg}$ body weight of the extract, respectively. After $30 \mathrm{~min}$, all the animals were administered $1 \mathrm{~mL}$ of charcoal meal (10\% charcoal suspension in 5\% nutrient agar), except for the animals in group I that received $1 \mathrm{~mL}$ of distilled water. The animals were sacrificed $30 \mathrm{~min}$ post-administration of the charcoal meal, following the procedure earlier described by Akanji and Yakubu (2000). The small intestine was excised for the computation of the peristaltic index using the following expression:

Peristaltic index $(\%)=\left(\begin{array}{c}\text { Distance travelled by } \\ \text { charcoal meal } \\ \text { Length of small intestine }\end{array}\right) \times 100$

[Eqn 2]

Thereafter, the activity of acetylcholine esterase and the level of nitric oxide were also determined.

\section{Preparation of small intestine supernatant}

The animals were sacrificed by adopting the procedure described by Akanji and Yakubu (2000). The rats were anaesthetised in diethyl ether fumes $(50 \mathrm{mg} / \mathrm{mL})$ after which their small intestine was removed from the dissected animals. The small intestine was emptied of the faecal contents, and blotted in blotting paper. The weight of the small intestine was determined, after which it was cut into thin pieces and homogenised in a $0.25 \mathrm{M}$ sucrose solution $(1: 5 \mathrm{w} / \mathrm{v})$ using a hand-held homogeniser (model D1000 Asteria Inc. New Jersey, United States [US]). The homogenates were immediately centrifuged (Uniscope Laboratory Centrifuge, model SM800B, Surgifield Medicals, England) at $1398 \times \mathrm{g}$ for $15 \mathrm{~min}$ after which the supernatants were aspirated and used within $12 \mathrm{~h}$ of preparation for the biochemical analyses.

\section{Determination of biochemical parameters}

The small intestine supernatants were assayed for the activities of $\mathrm{Na}^{+} / \mathrm{K}^{+}$-ATPase (Bewaji, Olorunsogo \& Bababunmi 1985; Ronner, Gazzotti \& Carafoli 1977), catalase (Beers \& Sizer 1952), SOD (Misra \& Fridovich 1972), alkaline phosphatase (Wright, Leathwood \& Plummer 1972), acetylcholine esterase (Ellman et al. 1961), and the concentrations of intestinal 
glucose (Trinder 1969), nitric oxide (Schmidt 1995), and reduced glutathione (Jollow et al. 1974).

\section{Statistical analysis}

The data obtained were expressed as a means \pm SEM (Standard Error of Mean) of seven replicates. The data were analysed using One-way Analysis of Variance and complemented with a Student's $t$-test. The Statistical Package for Social Sciences, Version 20.0 (SPSS. Inc., Chicago, IL, US) was used for data analysis and considered statistically significant at $p<0.05$.

\section{Ethical consideration}

University of Ilorin, Ilorin, Nigeria, Department of Biochemistry, Date: 12/10/2017, Approval Number: BCH/ UIL/15/2018.

\section{Results}

\section{Secondary metabolite screening}

The aqueous extract of C. planchonii leaves contained phenolics, saponins, tannins, alkaloids, flavonoids, terpenoids,

TABLE 1: Secondary metabolite constituents of aqueous extract of Cochlospermum planchonii leaves.

\begin{tabular}{lc}
\hline Secondary metabolites & Concentration $(\mathrm{mg} / \mathrm{L})$ \\
\hline Phenolics & $1.26 \pm 0.01$ \\
Saponins & $10.41 \pm 0.01$ \\
Tannins & $0.96 \pm 0.02$ \\
Alkaloids & $16.05 \pm 0.03$ \\
Flavonoids & $6.25 \pm 0.00$ \\
Cardiac glycosides & $11.38 \pm 0.01$ \\
Quinones & $0.71 \pm 0.01$ \\
Terpenoids & $1.05 \pm 0.03$ \\
Coumarins & $4.83 \pm 0.02$ \\
Steroids & Not detected \\
\hline
\end{tabular}

Values are means \pm SEM of 3 replicates.

SEM, standard error of mean. cardiac glycosides, quinones and coumarins, whilst steroids were not detected (Table 1). Alkaloids (16.05 mg/L) were the most abundant whilst quinones $(0.71 \mathrm{mg} / \mathrm{L})$ were the least abundant of the secondary metabolites in the aqueous extract of C. planchonii leaves (Table 1).

\section{Effects on castor oil-induced diarrhoea}

The aqueous extract of $C$. planchonii leaves significantly $(p<0.05)$ delayed the onset of diarrhoeal episodes at all of the doses investigated, whereas the faecal parameters (total number, number of wet, fresh weight and water content of faeces) were significantly, and dose-dependently, decreased (Table 2). Similarly, there was a dose-dependent increase in the percentage inhibition of defecation with the $500 \mathrm{mg} / \mathrm{kg}$ body weight of the extract exhibiting inhibition of defecation that was higher than that of the loperamidetreated rats. The concentration of intestinal glucose was reduced by the $125 \mathrm{mg} / \mathrm{kg}$ body weight of the extract whereas the 250 and $500 \mathrm{mg} / \mathrm{kg}$ body weight of the extract produced intestinal glucose levels that compared favourably $(p<0.05)$ with that of non-diarrhoeal, distilled water-treated rats. The loperamide-treated diarrhoeal rats produced a significantly higher level of intestinal glucose when compared with the non-diarrhoeal, distilled watertreated, control female rats. In addition, all of the doses of the extract dose-dependently increased the levels of intestinal nitric oxide (NO) when compared with the non-diarrhoeal, distilled water-treated rats (Table 2). The 125, 250 and $500 \mathrm{mg} / \mathrm{kg}$ body weight of the extract significantly increased the activity of $\mathrm{Na}^{+} / \mathrm{K}^{+}$-ATPase. The 250 and $500 \mathrm{mg} / \mathrm{kg}$ body weight of the extract significantly $(p<0.05)$ increased the intestinal alkaline phosphatase activity whereas the enzyme activity was not significantly increased by the $125 \mathrm{mg} / \mathrm{kg}$ body weight of the extract. All the doses of the extract did not significantly $(p<0.05)$ alter the activity of catalase (CAT) (Table 2). The levels of reduced

TABLE 2: Effects of aqueous extract of Cochlospermum planchonii leaves on castor oil-induced diarrhoea in female Wistar rats.

\begin{tabular}{|c|c|c|c|c|c|c|}
\hline \multirow{2}{*}{$\begin{array}{l}\text { Grouping } \\
\text { Dose in } \mathrm{mg} / \mathrm{kg} \text { body weight }\end{array}$} & \multirow{2}{*}{$\begin{array}{c}\text { Distilled } \\
\text { water }\end{array}$} & \multirow{2}{*}{$\begin{array}{c}\text { Castor oil + distilled } \\
\text { water }\end{array}$} & \multirow{2}{*}{$\begin{array}{c}\text { Castor oil + loperamide } \\
2.50\end{array}$} & \multicolumn{3}{|c|}{ Castor oil + Plant extract } \\
\hline & & & & 125 & 250 & 500 \\
\hline Onset time (minutes) & $0.00 \pm 0.00 \dagger$ & $83.40 \pm 1.17 \ddagger$ & $177.41 \pm 0.88 \S$ & $116.67 \pm 1.459$ & $121.33 \pm 1.76 \dagger \dagger$ & $158.67 \pm 4.97+4$ \\
\hline Total number of faeces & $3.67 \pm 0.33 \dagger$ & $12.67 \pm 0.67 \ddagger$ & $8.00 \pm 0.58 \S$ & $9.00 \pm 0.58 \S$ & $7.67 \pm 0.33 \S$ & $6.67 \pm 0.28$ \\
\hline Number of wet faeces & $0.00 \pm 0.00 \dagger$ & $11.33 \pm 0.88 \dagger$ & $4.33 \pm 0.33 \S$ & $7.00 \pm 0.58$ & $5.33 \pm 0.88 \S$ & $3.67 \pm 0.58 \S$ \\
\hline Fresh weight of faeces (g) & $0.17 \pm 0.03 \dagger$ & $4.93 \pm 0.84 \ddagger$ & $2.13 \pm 0.43 \S$ & $2.57 \pm 0.38 \S$ & $2.33 \pm 029 \S$ & $1.21 \pm 0.219$ \\
\hline Water content of faeces $(\mathrm{mL})$ & $0.02 \pm 0.01 \dagger$ & $2.43 \pm 0.12 \ddagger$ & $1.13 \pm 0.12 \S$ & $1.63 \pm 0.09$ & $1.17 \pm 0.09 \S$ & $0.69 \pm 0.09 \dagger \dagger$ \\
\hline Inhibition of defecation (\%) & 100 & 0 & 37.0 & 29.1 & 40.3 & 47.2 \\
\hline Intestinal nitric oxide $(\mu \mathrm{moL} / \mathrm{L})$ & $12.76 \pm 0.22 \dagger$ & $20.9 \pm 0.53 \$$ & $16.09 \pm 0.93 \S$ & $19.19 \pm 1.61 \dagger$ & $27.74 \pm 1.00 \S$ & $35.54 \pm 0.84 \uparrow$ \\
\hline Intestinal glucose $(\mu \mathrm{moL} / \mathrm{L})$ & $35.05 \pm 1.30 \dagger$ & $31.21 \pm 0.55 \ddagger$ & $47.95 \pm 0.07 \S$ & $31.21 \pm 0.85 \ddagger$ & $36.86 \pm 0.40 \dagger$ & $37.99 \pm 1.15 \dagger$ \\
\hline $\mathrm{Na}^{+} / \mathrm{K}^{+}$-ATPase $(\mu \mathrm{Pi} / \mathrm{mg}$ protein $/ \mathrm{hr})$ & $170.76 \pm 5.18 \dagger$ & $152.13 \pm 5.84 \$$ & $179.15 \pm 3.64 \uparrow \S$ & $183.47 \pm 8.60 \dagger$ & $234.09 \pm 9.13 \dagger$ & $281.74 \pm 5.02 \S$ \\
\hline Alkaline phosphatase (IU/L) & $30.19 \pm 1.29 \dagger$ & $17.67 \pm 0.46 t$ & $33.86 \pm 0.44 \S$ & $28.37 \pm 0.74 \dagger$ & $33.24 \pm 0.34 \S$ & $34.47 \pm 1.28 \S$ \\
\hline Catalase (kU) & $0.59 \pm 0.06 \dagger$ & $0.71 \pm 0.01 \%$ & $0.65 \pm 0.01 \uparrow$ & $0.59 \pm 0.02 \uparrow$ & $0.61 \pm 0.01 \dagger$ & $0.63 \pm 0.02 \dagger$ \\
\hline Reduced glutathione $(\mu \mathrm{moL} / \mathrm{mL} / \mathrm{min})$ & $1.27 \pm 0.02 \uparrow$ & $1.51 \pm 0.02 \ddagger$ & $1.14 \pm 0.05 \S$ & $1.47 \pm 0.06 \ddagger$ & $1.38 \pm 0.07 \ddagger$ & $1.00 \pm 0.08 \S$ \\
\hline
\end{tabular}

Values are means \pm SEM of seven determinations.

$\dagger$, Test values are significantly different at $p<0.05$.

$\downarrow, \S, \tau, \dagger \dagger,+\neq$, Test values are different from that of the distilled water-treated control, $\dagger$, for each parameter.

SEM, standard error of mean. 
glutathione (GSH) and SOD were increased by the 125 and $250 \mathrm{mg} / \mathrm{kg}$ body weight of the extract, whereas the $500 \mathrm{mg} / \mathrm{kg}$ body weight of the extract significantly $(p<0.05)$ reduced both of the levels of reduced glutathione (GSH) and SOD in the intestine of the animals, when compared with their respective non-diarrhoeal, distilled water-treated control animals (Table 2).

\section{Effects on castor oil-induced enteropooling}

The aqueous extract of $C$. planchonii leaves significantly $(p<0.05)$ reduced the masses and volumes of the intestinal fluid in a dose-dependent manner. Furthermore, the highest inhibition of intestinal content (47.00\%) was exhibited by the extract at $500 \mathrm{mg} / \mathrm{kg}$ body weight whilst the least inhibition $(20.50 \%)$ was by the $125 \mathrm{mg} / \mathrm{kg}$ body weight of the extract as against $41.50 \%$ by atropine sulphate (Table 3).

\section{Effects on charcoal meal transit}

The aqueous extract of $C$. planchonii leaves significantly $(p<0.05)$ inhibited the distance travelled by the charcoal meal in the small intestine in a dose-dependent manner. The peristaltic index was reduced in a dose-dependent manner whereas the computed percentage inhibition of peristalsis increased in a dose-dependent manner with the $500 \mathrm{mg} / \mathrm{kg}$ body weight producing values that were similar with those of the atropine sulphate-treated rats (Table 4). The activity of acetylcholinesterase (AChE) and the concentration of nitric oxide (NO) were significantly $(p<0.05)$ and dose-dependently increased in all the diarrhoeal rats that received the 125, 250 and $500 \mathrm{mg} / \mathrm{kg}$ body weight of the extract, when compared with their respective distilled water-treated diarrhoeal rats (Table 4).
It is noteworthy that the $250 \mathrm{mg} / \mathrm{kg}$ body weight produced NO level and AChE activity that compared favourably with the non-diarrhoeal, distilled water-treated female rats (Table 4).

\section{Discussion}

From time immemorial, herbal medicine has been the panacea for primary healthcare due to its perceived efficacy, availability, affordability and ancestral experience. However, more than $75 \%$ of these medicinal plants are yet to be substantiated or refuted with scientific claims. Hence, this study was designed to determine the secondary metabolite constituents, and proffer scientific credence to the folkloric use of the aqueous extract of Cochlospermum planchonii leaves as an anti-diarrhoeal plant, using standard diarrhoeal models.

Castor oil is degraded by lipase to ricinoleic acid in the intestinal lumen, a large amount of which is absorbed (Ammon, Thomas \& Philips 1974). Ricinoleic acid produces local irritation and inflammation of the intestinal mucosa by influencing the $\mathrm{NO}$ and prostaglandin pathways, causing the release of endogenous mediators such as $\mathrm{NO}$ and prostaglandins that stimulate motility, net secretion of water and electrolytes (Mbagwu \& Adeyemi 2008). This effect could also occur due to the capability of ricinoleic acid to activate the $G$ protein-coupled prostanoid receptor (EP3) on the smooth muscle cell of the intestine (Tunaru et al. 2012).

The aqueous extract of C. planchonii leaves at all the doses investigated prolonged the onset of diarrhoeal episodes, decreased stool frequency, the number of wet faeces, the fresh weight and water content of faeces, all of which alludes to its efficacy as an anti-diarrhoeal agent. Aside from regulating the gastrointestinal tract, loperamide has also been reported to slow down small intestinal transit, reduce

TABLE 3: Effects of the aqueous extract of Cochlospermum planchonii leaves on castor oil-induced enteropooling in female Wistar rats.

\begin{tabular}{|c|c|c|c|c|c|c|}
\hline Animal grouping & Distilled water & Castor oil + distilled water & Castor oil + atropine sulphate & & tor oil + Plant & \\
\hline Parameters/dose (mg/kg body weight) & 0 & 0 & 1.0 & 125 & 250 & 500 \\
\hline Mass of intestinal fluid (g) & $1.67 \pm 0.15 \dagger$ & $3.37 \pm 0.152 \%$ & $1.97 \pm 0.12 \S$ & $2.67 \pm 0.179$ & $2.07 \pm 0.12 \S$ & $1.77 \pm 0.19 \dagger$ \\
\hline Volume of intestinal fluid $(\mathrm{mL})$ & $1.63 \pm 0.09 \dagger$ & $2.13 \pm 0.18$ & $1.90 \pm 0.15 \dagger \ddagger$ & $2.60 \pm 0.12 \S$ & $1.70 \pm 0.17 \dagger$ & $1.53 \pm 0.14 \dagger$ \\
\hline Inhibition of intestinal content (\%) & - & 0.00 & 41.50 & 20.50 & 38.00 & 47.00 \\
\hline
\end{tabular}

Values are means of seven determination \pm SEM.

$\dagger$, Test value parameter are significantly different at $p<0.05$.

$\ddagger, \S, \boldsymbol{q}$, Test values are different from that of the distilled water-treated control, $\dagger$, for each parameter.

SEM, standard error of mean.

TABLE 4: Effects of aqueous extract of Cochlospermum planchonii leaves on charcoal meal transit in female Wistar rats.

\begin{tabular}{|c|c|c|c|c|c|c|}
\hline Animal grouping & Distilled water & Castor oil + distilled water & Castor oil + atropine sulphate & & or oil + Plant ex & \\
\hline Parameters/dose (mg/kg body weight) & 0 & 0 & 1.0 & 125 & 250 & 500 \\
\hline Length of intestine $\left(\mathrm{cm}^{3}\right)$ & $63.17 \pm 1.67 \dagger$ & $63.73 \pm 0.62 \ddagger$ & $70.77 \pm 0.87 \S$ & $72.27 \pm 0.70 \S$ & $72.20 \pm 0.30 \S$ & $69.43 \pm 0.73 \S$ \\
\hline Distance travelled by charcoal meal $\left(\mathrm{cm}^{3}\right)$ & - & $59.86 \pm 4.70 \dagger$ & $23.05 \pm 2.30 \%$ & $42.25 \pm 0.21 \S$ & $35.10 \pm 0.119$ & $20.87 \pm 2.01 \%$ \\
\hline Peristaltic index & - & 93.93 & 32.57 & 58.46 & 48.62 & 30.06 \\
\hline Inhibition of peristalsis (\%) & - & 0.00 & 61.49 & 29.42 & 41.36 & 65.14 \\
\hline Nitric oxide $(\mu \mathrm{moL} / \mathrm{L})$ & $53.69 \pm 3.06 \dagger$ & $48.67 \pm 0.34 \ddagger$ & $81.62 \pm 0.42 \S$ & $79.72 \pm 2.29$ & $79.35 \pm 2.30 \dagger$ & $84.48 \pm 4.30 \S$ \\
\hline Acetylcholinesterase $(\mu \mathrm{g} / \mathrm{mL})$ & $4.72 \pm 0.12 \dagger$ & $1.52 \pm 0.18$ & $7.84 \pm 0.58 \S$ & $12.91 \pm 0.05$ & $19.87 \pm 0.17 \dagger$ & $27.21 \pm 0.41 \S$ \\
\hline
\end{tabular}

Values are means \pm SEM of seven determinations.

$\dagger$, Test values are significantly different at $p<0.05$.

$\ddagger, \S, \boldsymbol{q}$, Test values are different from that of the distilled water-treated control, $\dagger$, for each parameter.

SEM, Standard Error of Mean. 
the colonic rate of flow and consequently increase colonic water absorption, but it does not have any effect on colonic motility (Theodorou et al. 1994). The aqueous extract of C. planchonii leaves at $500 \mathrm{mg} / \mathrm{kg}$ body weight exhibited the most profound anti-diarrhoeal activity as evidenced from the percentage inhibition of defecation, which was higher than the reference drug, loperamide, in this instance. This implies that the extract might have impacted more on the intestinal motility, unlike loperamide, and consequently enhanced the anti-diarrhoeal activity of the plant extract.

Nitric oxide, being a major cell signalling molecule, exerted its activity primarily by activating soluble guanylate cyclase and, thus, activated cyclic guanosine monophosphate dependent kinases which stimulates net secretion of fluid over reabsorption (Arthur et al. 2014). The increase in concentration of $\mathrm{NO}$ by the plant extract suggests the extract possesses metabolite(s) capable of enhancing the biochemical changes involved in the activation of the nitric oxide pathway and/or their intermediates.

The $\mathrm{Na}^{+} / \mathrm{K}^{+}$-ATPase is responsible for establishing and maintaining high intracellular $\mathrm{K}^{+}$and low intracellular $\mathrm{Na}^{+}$ concentrations that result in a favourable intracellular gradient (Karlish et al. 2008). The nutrient-coupled uptake of $\mathrm{Na}^{+}$entry across the brush border membrane, which in turn, stimulates $\mathrm{Na}^{+}$extrusion across the basolateral membrane of the cell through $\mathrm{Na}^{+} / \mathrm{K}^{+}$-ATPase is essential for efficient nutrient absorption and the subsequent maintenance of good health (Prosenjit et al. 2015). However, ricinoleic acid forms ricinoleate salts with $\mathrm{Na}$ and $\mathrm{K}$ in the intestinal lumen which inhibit $\mathrm{Na}^{+} / \mathrm{K}^{+}$-ATPase, thus impairing the gut barrier by increasing the permeability of the intestinal epithelium which produces a cytotoxic effect on intestinal absorptive cells (Komal \& Rana 2013). The increase in the activity of $\mathrm{Na}^{+} / \mathrm{K}^{+}$-ATPase by the plant extract, in the present study, might be attributed to the $\mathrm{Na}^{+}$/glucose co-transporter (SGLT1) which is the major route for the transport of dietary glucose from intestinal lumen into enterocytes, thereby enhancing the activity of the enzyme and, consequently, relieving the small intestine of water and electrolytes hypersecretion via the regulation of epithelial permeability (Chen, Tuo \& Dong 2016). Hence, the enhanced production of intestinal glucose and $\mathrm{Na}^{+} / \mathrm{K}^{+}$-ATPase might be one of those mechanisms by which the aqueous extract of C. planchonii exerts its anti-diarrhoeal activity.

The intestinal alkaline phosphatase, a component of the gut mucosal defence system, has the ability to detoxify lipopolysaccharide and act as a barrier for the invasion of microbes and toxins across the gut mucosal without compromising its absorptive function (Jan et al. 2017; Lalles 2014). During diarrhoea, there is impairment of the gut barrier function leading to reduced activity of the intestinal alkaline phosphatase. The restoration of the activity of intestinal alkaline phosphatase, in extract-treated diarrhoeal rats, might be an indication that the extract conferred a protective effect on the intestinal mucosa, thereby alleviating the episode of diarrhoea.
The decrease in mass and volume, of the intestinal content of the diarrhoeal rats treated with the aqueous extract of C. planchonii leaves, further alludes to the anti-diarrhoeal activity of the extract as this implies that the absorption of fluids and electrolytes were enhanced by the extract in this study. This is evident from the increase in the percentage inhibition of intestinal fluid accumulation in the present study.

The main function of the gastrointestinal tract is the transportation of food for digestion, absorption and excretion. Activated charcoal prevents the absorption of drugs and other chemicals into the body by absorbing them on the surface of the charcoal particles. Thus, the ability of all the doses of the plant extract in the present study, to suppress the propulsive movement of charcoal meal, is an indication that the extract possesses an anti-motility effect by decreasing the motility and consequently prolonging the absorption time for fluids and electrolytes. Intestinal motility and peristalsis are coordinated through the enteric nervous system where nitric oxide acts as the principal inhibitory neurotransmitter that mediates non-cholinergic and non-adrenergic relaxation of smooth muscle cells and interstitial cells of Cajal (Bult et al. 1990; Sanders 1996). Nitric oxide confers a protective effect and helps to maintain the integrity of intestinal epithelial cells when there is proper regulation in the de novo synthesis (Vallance et al. 2004). However, when the level of NO is elevated, it might be suggestive of a broad spectrum of pathophysiological conditions (Arthur et al. 2014). The dose-dependent increase in the level of serum NO in the diarrhoeal-rats treated with the aqueous extract of $C$. planchonii leaves might be indicative of proper regulation in the biological function of the small intestine.

Acetylcholine, an excitatory neurotransmitter, is released from cholinergic neurons and binds to the cholinergic receptors of the small intestine to facilitate peristalsis. However, AChE functions to terminate the transmission of cholinergic synapse via the hydrolysis of acetylcholine to form acetic acid and thiocholine (Beri et al. 2013). Atropine sulphate acts as an anticholinergic agent stimulating the hydrolytic function of AChE. The activity of AChE was enhanced by the aqueous extract of the C. planchonii leaves. The inhibition of peristalsis by the extract at 250 and $500 \mathrm{mg} / \mathrm{kg}$ body weight, which was similar to that of atropine sulphate, might therefore be attributed to the anti-motility function of the C. planchonii leaves via the stimulation of AChE.

During diarrhoea, there is an increased generation of reactive oxygen and/or nitrogen species (ROS/RNS) which may result in cellular oxidative stress that can be detrimental to the enterocytes (Bhattacharyya et al. 2014). Antioxidants such as SOD, catalase and reduced glutathione are involved in protecting cells from the damaging effects of these ROS/ RNS. The attenuation of GSH, SOD and catalase (CAT) in the extract-treated diarrhoeal rats suggests the mitigation of 
oxidative stress on the enterocytes, thereby protecting the integrity of the intestinal mucosa.

Although secondary metabolites are produced by wide varieties of plants as defence compounds against herbivores, and other plants and microbes, some have been implicated with anti-diarrhoeal activity. Phenolics possess antioxidant properties mainly due to their redox properties, which allow them to act as reducing agents, hydrogen donors and singlet oxygen quenchers in metabolisms that occur in the small intestine (El-Seedi \& Nishiyama 2002). Saponins inhibit the release of histamines, known to induce diarrhoea, whereas tannins form protein tannates that coat the surface of intestinal mucosa, thereby reducing secretion (Hamalainen et al. 2011; Wang et al. 2010). Furthermore, flavonoids inhibit intestinal motility and prostaglandin E-2 induced secretion (Tiwari et al. 2011). Coumarins and some quinones are also regarded as potential antioxidants as a result of their ability to scavenge free radicals and to chelate metal ions (Tseng 1991). The antioxidant activity exhibited by the aqueous extract of $C$. planchonii leaves might be attributed to the presence of coumarins, flavonoids, alkaloids, saponins and phenolics.

\section{Conclusion}

This study provided scientific credence to the folkloric use of the aqueous extract of C. planchonii leaves as an anti-diarrhoeal agent. The plant exhibited anti-secretory and anti-motility effects as evidenced from the stimulation of the $\mathrm{Na}^{+} / \mathrm{K}^{+}$-ATPase, antioxidant system, intestinal glucose and alkaline phosphatase whilst upregulating the biosynthesis of acetylcholine esterase. The anti-diarrhoeal activity of C. planchonii leaves, as demonstrated in this study, can be attributed to the coumarins, phenolics, saponins and flavonoids that might have acted singly or synergistically. The isolation and characterisation of bioactive components will be a focus for further studies.

\section{Acknowledgements Competing interests}

The authors have declared that no competing interest exists.

\section{Authors' contributions}

M.T.Y. designed the work and proofread the manuscript for intellectual content. O.D.A., M.O.M., C.I.A., J.O.A. gathered the data and drafted the manuscript. S.S.S. corrected the draft manuscript. S.A.O. drafted the manuscript and checked for statistical analysis.

\section{Funding information}

This research received no specific grant from any funding agency, in the public, commercial, or not-for-profit sector.

\section{Data availability statement}

Data sharing is applicable to this article as new data were created or analysed in this study.

\section{Disclaimer}

The views and opinions expressed in this article are those of the authors and do not necessarily reflect official policy or position of any affiliated agency of the authors.

\section{References}

Abu, A.H., Ochalefu, D.O. \& Ibrahim, A., 2012, 'Aqueous ethanolic extract of Cochlospermum planchonii rhizome enhances spermatogenesis in male Wistar rats', African Journal of Biotechnology 11(53), 11636-11639. https://doi. org/10.5897/AJB12.225

Adelakun, S.A., Akinola, B.K. \& Akingbade, G.T., 2018, 'Fertility enhancing activities of bioactive components of Cochlospermum planchonii rhizome on cisplatin-induced reproductive dysfunctions in Sprague-Dawley rats', Journal of Family and Reproductive Health 12(3), 148-159.

Adjanahoun, E., Ahyi, M.R.A., Ake-Assi, L., Elewude, J.A., Dramane, K., Fadoju, S.O. et al., 1991, Traditional medicine and pharmacopoeia, contribution to ethnobotanical floristic studies in Western Nigeria, Pub. Organization of African Unity, Scientific Technical and Research Commission, Lagos, Nigeria. p. 420.

Akanji, M.A. \& Yakubu, M.T., 2000, ' $\alpha$-tocopherol protects against metabisulphateinduced tissue damage in rats', Nigerian Journal of Biochemistry and Molecular Biology 15(2), 179-183.

Ammon, H.V., Thomas, P.J. \& Philips, S., 1974, 'Effects of oleic and ricinoleic acids on net jejunal water and electrolyte movement', Journal of Clinical Investigation 53 , 374-379. https://doi.org/10.1172/JCl107569

Arthur, S., Coon, S., Kekuda, R. \& Sundaram, U., 2014, 'Regulation of sodium glucose co-transporter SGLT1 through altered glycosylation in the intestinal epithelial cells', Biochimica et Biophysica Acta (BBA)-Biomembranes 1838(5), 1208-1214. https://doi.org/10.1016/j.bbamem.2014.01.002

Ashafa, A.O. \& Nafiu, M.O., 2018, 'Antidiabetic activity and free radicals modulatory potentials of saponin-rich extract of Cochlospermum planchonii (Hook Fx. Planch) root in vitro', Comparative Clinical Pathology 27(2), 313-320. https://doi org/10.1007/s00580-017-2590-4

Bamisaye, F.A., Sulyman, A.O., Abegunde, R. \& Ajani, E.O., 2017, 'Antidiabetic and antidyslipidemic activities of the aqueous extract of Cochlospermum planchonil leaves in streptozotocin-induced diabetic rats', Iranian Journal of Medical Sciences 42(6), 553-560.

Beers, R.F. \& Sizer, I.W., 1952, 'A spectrophotometric method for measuring the breakdown of hydrogen peroxide by catalase', Journal of Biological Chemistry 195, 133-140.

Beniot-Vical, F., Vaaletin, A., Da. B., Dakuyo, Z., Descamps, L. \& Mallie, M., 2003 'N'Dribala (Cochlospermum planchonii) versus chloroquine for treatment of uncomplicated Plasmodium falciparum malaria', Journal of Ethnopharmacology 89(1), 111-114. https://doi.org/10.1016/S0378-8741(03)00277-0

Beri, V., Auletta, J.T., Maharvi, G.M., Wood, J.F., Fauq, A.H. \& Rosenberry, T.L., 2013 'Hydrolysis of low concentrations of the acetylthiocholine analogs acetyl (homo) thiocholine and acetyl thiocholine by acetylcholinesterase may be limited by selective gating at the enzyme peripheral site', Chemico-Biological Interaction 203(1), 38-43. https://doi.org/10.1016/j.cbi.2012.09.017

Bewaji, C.O., Olorunsogo, O.O. \& Bababunmi, E.A., 1985, 'Comparison of the membrane-bound $\left(\mathrm{Ca}^{2+}-\mathrm{Mg}^{2+}\right)$-ATPase in erythrocyte ghosts from some mammalian species', Comparative Biochemistry and Physiology 82(1), 117-122. https://doi.org/10.1016/0305-0491(85)90138-5

Bhattacharyya, A., Chattopadhyay, R., Mitra, S. \& Crowe, S.E., 2014, 'Oxidative stress: An essential factor in the pathogenesis of gastrointestinal mucosal diseases', Pathophysiological Reviews 94(2), 329-354. https://doi.org/10.1152/ physrev.00040.2012

Bult, H., Boeckxstaens, G.E., Pelckmans, P.A., Jordaens, F.H., Van, M.Y.M. \& Herman, A.G., 1990, 'Nitric oxide as an inhibitory non-adrenergic non-cholinergic neurotransmitter', Nature 345(6273), 346-347. https://doi.org/10.1038/ $345346 \mathrm{aO}$

Burkill, H.M., 1985, 'The useful plants of West Tropical Africa', Royal Botanical Gardens, Kew 1(2), 386-960.

Chen, L., Tuo, B. \& Dong, H., 2016, 'Regulation of intestinal glucose absorption by ion channels and transporters', Nutrients 8(1), 43. https://doi.org/10.3390/ nu8010043

Ellman, G.I., Courtney, K.D., Andres, V. \& Featherstone, R.M., 1961, 'A new and rapid colorimetric determination of acetylcholinesterase activity', Biochemical Pharmacology 7, 88-95. https://doi.org/10.1016/0006-2952(61)90145-9

El-Olemy, M.M., Al-Muhtadi, F.J. \& Afifi, A.A., 1994, Experimental phytochemistry. A laboratory manual, King Saud University Press, Riyadh, pp. 3-137.

El-Seedi, H.R. \& Nishiyama, S., 2002, 'Chemistry of bioflavonoids', Indian Journal of Pharmaceutical Education 36(4), 191-202. 
Ezeja, M.I., Ezeigbo, I.I., Madubuike, K.G., Udeh, N.E., Ukweni, I.A., Akomas, S.C., et al. 2012, 'Antidiarrhoeal activity of Pterocarpus erinaceus methanol leaf extract in experimentally-induced diarrhoea', Asian Pacific Journal of Tropical Medicine 5(2) 147-150. https://doi.org/10.1016/S1995-7645(12)60014-5

Gerald, N.T., Jules, R.K., Omer, B.N. \& Donatien, G., 2007, 'Antidiarrhoeal and antimicrobial activities of Emilia coccinea (Sims) G. Don extracts', Journal of Ethnopharmacology 112, 278-283. https://doi.org/10.1016/j.jep.2007.03.007

Hamalainen, M., Nieminen, R., Asmawi, M.Z., Vuorela, P., Vapaatalo, H. \& Moilanen, E., 2011, 'Effects of flavonoids on prostaglandin E-2 production and on COX-2 and mPGES-1 expressions in activated macrophages', Planta Medica 77(13) 1504-1511. https://doi.org/10.1055/s-0030-1270762

Harborne, J.B., 1973, Phytochemical methods: A guide to modern techniques of plan analysis, Chapman \& Hall Ltd, London, pp. 149-188.

Havagiray, R., Ramesh, C. \& Sadhna, K., 2004, 'Study of antidiarrhoeal activity of Calotropis gigantea R.B.R. in experimental animals', Journal of Pharmaceutical Science 7, 70-75.

Hudson, B.J.F. \& El-Difrawi, E.A., 1979, 'The sapogenins of the seeds of four Lupin species', Journal of Plant Foods 3, 181-186. https://doi.org/10.1080/014296 8X.1979.11904227

Ior, L.D., Uguru, M.O., Olotu, P.N., Ohemu T.L. \& Ukpe, A., 2011, 'Evaluation of analgesic and anti-inflammatory activities and phytochemical screening of the leaves extract of Paullinia pinnata (Sapindaceae)', Journal of Chemical and Pharmaceutical Research 3(4), 351-356.

Jan, B., Agnieszka, M., Dagmara, W., Janina, Z., Bartosz, B., Marcin, M., et al., 2017 'The role of intestinal alkaline phosphatase in inflammatory disorders of gastrointestinal tract', Mediators of Inflammation 2017, 9074601. https://doi. org $/ 10.1155 / 2017 / 9074601$

Jollow, D.J., Mitchell, J.R., Zampaglione, N. \& Gillete, J.R., 1974, 'Bromobenzeneinduced liver necrosis: Protective role of glutathione and evidence for 3,4 bromobenzene oxide as the hepatotoxic metabolite', Pharmacology 11, 151-169. https://doi.org/10.1159/000136485

Karlish, S.J., Tal, D., Katz, A., Kapri-Pardes, E., Belogus, E, Haviv, H., et al., 2008, The sodium-potassium pump: Structure, function, regulation and pharmacology, Life Science Open Day, Weizmann Institute of Science, Rehovot, Israel, pp. 1-3.

Komal, K.S. \& Rana, A.C., 2013, 'Herbal approaches for diarrhoea: A review', International Research Journal of Pharmacy 4(1), 323-331.

Lalles, J.P., 2014, 'Intestinal alkaline phosphatase: Novel functions and protective effects', Nutrition Reviews 72(2), 82-94. https://doi.org/10.1111/nure.12082

Lamaison, J.L.C. \& Carnet, A., 1990, 'Teneurs en principaux flavonoids des fleurs de Crataegeus monogyna Jacq et de Crataegeus laevigata (Poiret D.C) en function de la vegetation', Pharmaceutica Acta Helvetiae 65, 315-320.

Mbagwu, H.O.C. \& Adeyemi, O.O., 2008, 'Antidiarrhoeal activity of the aqueous extract of Mezoneuron benthamianum Baill (Caesalpinaceae)', Journal of Ethnopharmacology 116, 16-20. https://doi.org/10.1016/j.jep.2007.10.037

Misra, H.P. \& Fridovich, I., 1972, 'The role of superoxide anion in the auto-oxidation of epinephrine and a simple assay for superoxide dismutase', Journal of Biological Chemistry 247, 3170-3175.

Nafiu, M.O., Akanji, M.A. \& Yakubu, M.T., 2011, 'Phytochemical and mineral constituents of Cochlospermum planchonii (Hook. Ef. x Planch) root', Bioresearch Bulletin 5, 342-347. https://doi.org/10.1007/s00580-012-1552-0

Nafiu, M.O., Akanji, M.A. \& Yakubu, M.T., 2013, 'Toxicity of aqueous root extract of Cochlospermum planchonii (an anti-malarial herb) in selected tissues of mice', Comparative Clinical Pathology 22(6), 1211-1218.

National Research Council (NRC), 2011, Guide for the care and use of laboratory animals, National Research Council (US) Committee for the Update of the Guide for the Care and use of Laboratory Animals (eds.)., 8th edn., National Academies Press, Washington, DC

Odebiyi, A. \& Sofowora, A.E., 1978, 'Phytochemical screening of Nigerian medicinal plants. Part III', Lloydia 41, 234-246.

Ouattara, L., Jean, K., Louis, C.E., Obama, D.S., Karou, A.T. \& Jean, M.B., 2007, 'Chemical Composition and Antibacterial Activity of Cochlospermum planchon Hook.f. ex Planch Essential Oil from Burkina Faso', Pakistan Journal of Biological Science 10(22), 4177-4179. https://doi.org/10.3923/pjbs.2007.4177.4179
Peter, A.K. \& Umar, U., 2018, 'Combating diarrhoea in Nigeria: The way forward', Journal of Microbiology Experiments 6(4), 191-197. https://doi.org/10.15406/ jmen.2018.06.00213

Prosenjit, S., Palanikumar, M., Subha, A., Shanmuga, S., Ramesh, K. \& Uma, S., 2015, 'Molecular mechanism of regulation of villus cell $\mathrm{Na}$-K-ATPase in the chronically inflamed mammalian small intestine', Biochimica et Biophysica Acta 1848 702-711. https://doi.org/10.1016/j.bbamem.2014.11.005

Ragazzi, E. \& Veronese, G., 1973. 'Quantitative analysis of phenolics compounds after thin layer chromatographic separation', Journal of Chromotography 77, 369-375. https://doi.org/10.1016/S0021-9673(00)92204-0

Ronner, P., Gazzotti, P. \& Carafoli, T., 1977, 'A lipid requirement for the $\left(\mathrm{Ca}^{2+}+\mathrm{Mg}^{2+}\right)$ activated ATPase of erythrocyte membranes', Archives of Biochemistry and Biophysics 179, 578-583. https://doi.org/10.1016/0003-9861(77)90146-1

Sanders, K.M., 1996, 'A case for interstitial cells of Cajal as pacemakers and mediators of neurotransmission in the gastrointestinal tract', Gastroenterology 111(2), 492-515. https://doi.org/10.1053/gast.1996.v111.pm8690216

Schmidt, H.H., 1995, 'Colorimetry assay for determination of total nitrite', Biochemica 2, 22-23.

Solich, P., Sedliakova, V. \& Karlicek, R., 1992, 'Spectrophotometric determination of cardiac glycosides by flow-injection analysis', Analytical Chimica Acta 269(2), 199-203. https://doi.org/10.1016/0003-2670(92)85403-S

Sunil, B., Bedi, K., Singla, A. \& Johri, R., 2001, 'Antidiarrhoeal activity of piperine in mice', Planta Medica 67, 284-287. https://doi.org/10.1055/s-2001-11999

Swain, T., 1979, 'Tannins and lignins', in G.A. Rosenthal \& D.H. Janzen (eds.), Herbivores: Their interaction with plant metabolites, pp. 355-388, Academic Press, New York.

Theodorou, V., Floramonti, J., Hachet, T. \& Bueno, L., 1994, 'Interleukin-1 induces a neurally mediated colonic secretion in rat involvement of mast cells and prostaglandins', Gastroenterology 106, 1494-1500. https://doi.org/10.1016/00165085(94)90402-2

Tiwari, P., Bimlesh, K., Mandeep, K., Gurpreet, K. \& Harleen, K., 2011, 'Phytochemical screening and extraction: A review', International Journal of Pharmaceutical Science 1(1), 98-106.

Togotla, A., Austerheim, I., Theis, A., Diallo, D. \& Paulsen, B.S., 2008, 'Ethnopharmacological uses of $E$. senegalensis: A comparism of three areas in Mali and a link between traditional knowledge and Modern biological science', Journal a link between traditional knowledge and Modern biological science', Journal
of Ethnobiology and Ethnomedicine 4(6), 1-9. https://doi.org/10.1186/17464269-4-6

Trinder, P., 1969, 'Determination of glucose in blood using glucose oxidase with on alternative oxygen receptor', Annals of Clinical Biochemistry 6, 24-27. https://doi. org/10.1177/000456326900600108

Tseng, A., 1991, 'Chemoprevention of tumors in MTV-H ras transgenic mice with coumarins', Proceedings of the American Association for Cancer Research 32, 2257.

Tunaru, S., Althoff, T.F., Nusing, R.M., Diener, M. \& Offermanns, S., 2012, 'Castor oil induces laxation and uterus contraction via ricinoleic acid activating prostaglandin EP3 receptors', Proceedings of the National Academy of Sciences of the United States of America 109(23), 9179-9184. https://doi.org/10.1073/pnas.1201627109

Vallance, B.A., Dijkstra, G., Qiu, B., Van der Waaij, L.A., Van Goor, H., Jansen, P.L., et al. 2004, 'Relative contributions of NOS isoforms during experimental colitis: Endothelial-derived NOS maintains mucosal integrity', American Journal of Physiology, Gastrointestinal \& Liver Physiology 287, G865-G874. https://doi. org/10.1152/ajpgi.00187.2004

Wang, G.S., Han, J., Zhao, L.W., Jiang, D.X., Liu, Y.T. \& Liu, X.L., 2010, 'Anthelmintic activity of steroidal saponins from Paris polyphylla', Phytomedicine 17, 1102-1105. https://doi.org/10.1016/j.phymed.2010.04.012

Wright, P.J., Leathwood, P.D. \& Plummer, D.T., 1972, 'Enzymes in rat urine: Alkaline phosphatase', Enzymologia 42, 317-327.

Yakubu, M.T., Akanji, M.A. \& Nafiu, M.O., 2010, 'Article original pharmacology antidiabetic activity of aqueous extract of Cochlospermum planchonii root in alloxaninduced diabetic rats', Cameroon Journal of Experimental Biology 6(2), 91-100. https://doi.org/10.4314/cajeb.v6i2.68526 